\title{
Financial and Political Causes behind Child Labor: The Case of Pakistan
}

\author{
* Zareen Qadeer, Lecturer \\ ** Dr. Urooj Talpur, Assistant Professor \\ *** Najia Shaikh, Assistant Profes sor
}

\begin{abstract}

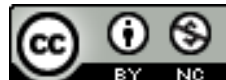

Working with teenagers is the world's driving judgment, particularly in agrarian countries, and Pakistan is in like way an overcomer of this making generally wonder for various reasons that are the legitimization the purposeful or amazing improvement of kid work. Youngster's work has prompted various results that have confused the social arrangement it has with the framework, and the progress of its decisions makes the Pakistani Government aware of take-away the finest and most sensible actions to combat this affront. The sign of this statement is to see the monetary and diplomatic purposes behind teenagers' work out and to research the matter via a mix of inspection procedures utilizing Confederation upgrades towards getting the veritable pith offered appraisal at multilateral spaces of income. The appraisal additionally reviews the ideas and evaluations made by philosophy creators for their execution.
\end{abstract}

Keywords: Financial, Definitive Issues, Child Labor, Socio-Economic, Politics.

\section{Introduction}

The destiny of every nation is in the responsibility for, as every country's youthfulness is committed to advance or the fall of their country. The state can intercede when youngsters are told and sensible. Likew ise, teenagers can be able as they continuously blend. The country can go to the skyline when youths are raised. The second these youthful occupants are picked for the Technote how they can deal with the destiny of the state in a prosperous procedure to rise to the remainder of the world. Amazingly, regardless, the fate of adolescents in common settlements is not so gotten. They expected to investigate the workplace ceaselessly. "As the International Labor Organization (ILO) clarifies, 250 million teenagers from 5 to 14 years of age work for the day or under upkeep." 120 million young people work with little help. They work in different spaces of progress, like present-day affiliations, affiliations, developing affiliations, and families. Overall affiliations and affiliations offer extra sorts of help to youths at Diel Mind (Bachmann's, 2001). Kidde's work is not the previous miracle. The establishments of this horrible supernatural occurrence get back to routine lifting throughout Zia-ulHaq, once here stayed an authentic need meant for work. Young people's remuneration costs are more reasonable than grownups, so kids are employed in made plants by entrepreneurs that are identified with their consequences, in any case regardless of their future. The most settled countries have found a course way to deal with battle kids' work and pass laws after World War II. The best movement is introduced once more, which has lessened the consumption of grind (Awake, etc., 2012).

After Rogoredo and Standup (1981), there were several plans of vivacious occupations. These-are programs are as per the going with:

** Wages

** Home business

** Unbureaucratic exercises were not seen during observation.

** Work with desserts.

Kid work is delicate against the perils of thriving and is especially helpless against authentic torment and injury (Levison and Murray-Close, 2005). Family work, schoolwork, mining, fishing, improvement, get-together, and development are limits including most youth laborers who are in danger of feeling good. The effect of standard conditions and specialists' changes beginning with one country then onto the following. The qualifications depend upon age and sexual course (Jones and O'Donnell, 2002). The inspiration is the clarification all young adult practices are not hurting/solid

* Social Work Department, University of Sindh Jamshoro Email: zareenqadeer7860@gmail.com

** Department of Economics, University of Sindh. Email: talpur.urooj@yahoo.com

*** Institute of Commerce University of Sindh, Jams horo Email: najia.shaikh@usindh.edu.pk 
and under-work out, for instance, childcare and occupation give them stunning learning openings. Regardless, prostitution, unlawful maltreatment, and disgusting headway are painful and mental settop boxes (Dressy) Dressy Pillage, 2003).

Affiliations are making remarkable endeavors to crush the scourge of adolescents and keep up laws that confine or bar society. A normal occasion all through the planet is that confining kid work is a terrible errand for fewer individuals' misfires like Pakistan. Learning is the most regarded and normal occasion that manages this improper occasion, which interests kids not to zero in on kids' work. Another issue might be the straightforwardness of thought. Without a doubt, in any event, coming about to being in the military, they cannot go any further in class.

\section{Child Labor in Pakistan}

In 1996, the Federal Bureau of Statistics, with the endeavor of the ILO, driven a public assessment of youngster work, showing that the measure of youths from 5 to 14 years old was forty billion as if these teenagers, 2001 (8.4\%) Economic activities. Of these youngster employees, 74\% are sons and $29 \%$ are females. In addition, a colossal number of these children are in Punjab-Province, the balance several spaces of Pakistan. Here as well, youngsters in normal and capital districts work more in like manner regions than in capital zones. In general, these youngsters were lifted $1 / 3$, and the others-as stayed not raised. Most acting adolescents are not reimbursed because they are exploited the same as specialists. While some of them are paid, they are barely against the more experienced laborers. Homes like the self-confident advantages of home credit holders. In any case, less is required in shops, shops two or three clubs. About $46 \%$ of kids generally worked 35 hours out of consistently, despite the seven-day 56-hour rate. This shows that there are relatively few of the most experienced time plan workers (Zaniest et al, 2013).

Awan features working with youngsters with various examination markers (MICS, 20072008). The place of the intermingling of his audit is on Punjabi Pakistan, and the consequences show that the maker is the fundamental motorist of late effort, the deficiency of rules from the Custodians. Gatekeepers who are non-instructed to set up the ir-as pre-adulthood to work as resisted to consider. They intend to get hard cash just from the ir children's wages. They have no nil in the predetermination of their-as youngsters, so when the ir-as kids are raised, they want to be an adult wealth for and the country. Similarly, the effect of this analysis shows that young associates have a higher number of youngsters living in the workspace than lively women (Awan, et al., 2011).

Regardless, Ahmad causes to see this joblessness, challenges, nonappearance of coaching, exhaust, and clinical idea are the standard segments convincing youngsters to work (Ahmad, 2012). The cash-related states of children make up it tricky to perceive kids among the age of ten and fourteen. Due to their guideline work, sexual separation among early school dropouts and school cooperation, speculations for youngsters, extraordinarily wedded and youths, are answerable for family chores (Kaolin \& Side, 2013). Direction for unsigned families is not hampered by a defic it of a useful structure and high joblessness. Thusly, the work out is wanted to give away limits that have paid off (Ahmadis, 2014).

\section{Causes \& Factors of Child Labor in Pakistan}

Children's work out is a predictable examination in the nation that bewilders the strategy for improvement (Kourases et al., 2004). As per the 1998 assessment on youngster worked, 8.28\% of youngsters of acting age are 3.8 billion of the forty billion (progressive). The Federal Bureau of Statistics, the ILO, and the Ministry of Labor will take part in the audit. Resulting to looking at the evaluations, it was discovered that adolescents worked in different spaces of work, for instance. B in block warming, planting, private undertakings, land, and floor covers. Some youthful specialists let their shoes shine, have a vehicle or a flying tracker cleaned around there/roads (Han, 2001).

The youngster is a country/humankind revolve around that needs security from all sociocurrent risks to the certified improvement of vigorous people (Swade \& Lokshen, 2000). Young adult specialists experience the loathsome impacts of playmate infirmity and are tended to by overpowering pollutions (Fossa et al., 1999). These youths have a limited number of responsibilities and extended occasions of work, which sway their psychosocial burdens of progress and learning and deny them to move in a fundamental direction.

\section{Poverty and Des titution in Proportion of Child Labor}

The youngster has a spot in powerless families," the kid's youth creates. There is an augmentation in grown-ups and changes in adolescents because of its different impacts and reasons. Adolescents in 
need deny kids and impact mental information, academic and languishing suggestions over the cerebrum and the existences of kids. Trouble additionally socially impacts different occasions in enormous distance overseeing and on the progress of youths (Ortiz, et al., .2014). Several experimental evaluations show the matter and showing the relation amongst reliable assumptions used for joint effort and youth employment. Clarify that children from lowest-paid relatives should go to work for young people, not kids with an occupation. The master saw this theme during the scrutinizing. Duryea's, Lame, and Levesons (2006) discovered that redundancy among crisis laborers was an added thing convincing their children to build up the secretly run company's. While Aqil (2012) perceives that youngsters', work makes from the age when educators work for adolescents, their childhood will work and make as insuffic ient and non-reliable people. This is what parent-school means for youngsters' school. Basich (2007) "sees that youngsters work without mentoring and without preparing, in this way influencing the improvement of the country and the economy".

\section{Re view \& Outline of Child Labor}

Youngsters are depended on to deal with the start of progress close to the flimsy edge of spilling, as they have made a careful appearance. In 1833 and 1844 it was fundamental to truly zero in on young people in a variety of purposes behind living. Regardless, there a few youths who continue to work, which the law denies (Bhat, 2011). There is no fixed and quantifiable adolescent exertion to review the update of child labor all concluded the earth. Record adolescent effort cases are unimportant seeing the mode that the experts cannot assemble info (Dess, 2011). The greatest standard and key category of adolescent labor is a close slog that controls youths. It does not rehearse public authority over affiliation, everything considered concerning internal structures, and is affected by the psychosocial and certifiable abuse of augmented periods of work. The public condition and society as space do not recognize the commitments concerning this have an impact to be certified and zero, so it is shocking to pick the specific number of these prepared subject matter experts. An adolescent's paid or unpredictable work rather than the far off has tumbled from "day-care" (Lyons and Vladivostok, 2011).

There are dissimilar shares that drive children to worked and enhance these quick pleasing questions. Most adolescents in under-acquitted families are associated with how their relatives do not consider all the socio-mental and truly prospering risks youths can go confronting. Considering their condition and the significance of cash-related assistance, these bosses are content with the advancement of youth affiliations (OHCHR, 2014). This is the customary market standard, low wages are gotten and stuffed by the owner, as this is a hard and covered occupation that is not vivaciously affected by the district's community energy. Young people's exertion at home loses the upside of our-s pioneer grow-together.

Contempt the shortfall of trustworthy location evaluations, the I.L.O (Aqil's, 2011) watches that 220 billion adolescents have made an advert in the level of five and seventeen and 120 billion people working in dangerous occupied environments. Improvement has the most stunning section of fully-grown work considering adolescents' to be as an issue, as agribusiness is at the point of convergence of the economy of all No ethanol nations (Baker, 2008). If all else fails, adolescents in normal zones are seen as a more essential number of workers than the replacements of the capital, as they need to progress and there are more unhinged ones (Amaro \& Dooce, 2011). To re-join the family, to pay weak families in open regions, young people are seen as wages through typical work (Serwadda-Luwaga, 2005).

In like way, there are standard regular segments in the metropolitan region in various plans like family tasks or action choices. In any case, working conditions are interesting, under pressure, and disastrous, and work for additional hours and low/zero wages. Youngsters are weaker than a huge segment of the ability to screen people about sexual viciousness and abuse under customary metropolitan factors. Vagrancy is the standard factor that prompts slight youths in the metropolitan territory not needing some interest in the care, government-administered retirement, and social accomplishment (Baker, 2008). There is no shortcoming that youths have a spot in the conurbations, which, inside seeing promising conditions and openings, have stunning freedoms that are ideal for young people in normal zones. Youngsters in like way territories fight with transportation and foundation, as schools are worked within a non-changing area, and this is a test for families (clear, 2008). Energetic workers and specialists are moreover moving, as you can see according to elective perspectives. In the relationship between mentor and adolescent work. The overall affiliation rate is 
low for adolescents in relative spaces (Edmonds, 2007). Area (2001) worked with the diagram in Pakistan's and Nepal-lain, where-as he recommended that "the instance of erotic position is wider in Pakistan's than in Nepalis. In Pakistan, your young aides will in all probability work lengthier hours provincial children are less substance with energetic industrialists, while in Nepal it is an exceptional inverse.

\section{The International Corporations}

The two effective people, the ILO and UNICEF, are attempting to kill by advancing various endeavors and helping governments with acclimating themselves or with show themselves. There are a few quick and abnormally kept progress projects. Improving clinical thinking and the chance of complaints are UNICEF's standard commitments. Mott made two works, picked to safeguard early persons from risky and abominable misuse, and gave them as what-to-do at fourteen ages of age. Teenagers are not allowed to work more than 14 people (Bhatt, 2010; close to the end in 2009). "Modesto" (2008) recommends that if a family does not have to head human necessities, any approach to manage a more energetic workspace is not fitting for society. Most nations have adolescent work laws, yet it is difficult to see states plainly, which can lead young people to have a family by not suggesting the planned approach.

In 1973, at 138 years of age, the I.L.O became a base showed, which was gotten by 162 states. The essential objective of the Pact is to usual up an age bound for young people. Children more vigorous than 15 should not work, as this impacts their prospering and course. Youngsters more vigorous than 13 cannot work feasibly and working conditions ongoing years old should not be unsafe and risky (Pew, etc., 2004). Mott called verbalization in 1999 the "most amazingly disturbing endeavor" and the 174 nations that passed the "most terrible kind of show on kid work" in 1999. In slight countries, youngsters think about unsafe exercises and do not have a key workspace; they join youngsters who need or sell around there (I.L.O, 2011).

The United Nations Agreement on the Human rights of the Children (.C.RC, 1988) covers 155 pieces of training. SKR sees that key instructing and statelessness must be basic. The advancement of non-compulsory getting ready and the like lihood that the collusion must be created. There are 05 work openings for adolescents in playschool. The S.K.R covers Training 01, 18, 29, 32, 35, and 37 on childhood effort (Aqil's, 2011).

Object 1: "Teens are known as individuals more vigorous than 18". (Aqil, 2012)

Article 19: "Youths should demand conviction against mercilessness and abuse". (Aqil, 2012) Article 28: "Teenagers should demand insurance from sexual viciousness and carelessness". (Aqil, 2012)

Article 32: "States that all young people ought to be safeguarded from abuse and hazardous work to keep kids from really zeroing in on them or obstructing their growing and improvement". (Aqil, 2012) Article 34: 'Children ought to get their consent for a key region'. (Aqil, 2012)

Article 1 and a huge piece of: "The young person will benefit by incalculable abuses". (Aqil, 2012) "The 2000 One-Millennium Declaration intends to show up at eight twenty to long stretch old for 2015, which is a separating debilitating and needing for lire; the advancement of customary key planning; driving comprehension and sex selection passed on by women; decreasing infant kid mortality, improving youth mental flourishing, engaging HIV/AIDS, wild fever and various issues; event improvement." (Rena, 2009).

\section{Re view of Lite rature}

Expression, Kachina, Dalgarno's and Restitches (1998), in the their-as savvy article "Kid-Labor and Health's: Glitches and Perspectives", find which working adolescents provision the family, so the last occupation is a productive new development, starting as shown by the point of view here. Since for the current condition there could be no more arranged relative who is gotten the message out about for the family, there is certainly not a functional option for young people to acquire the family. Notwithstanding, this is similarly unsafe for adolescents, as the workspace is not incredible and has no effects that build up teens. "Cigna, A., Rosati, F. moreover, Guario, L. (2002)" in the article "Developing youths' work?" perceives that a central piece of children's work is flourishing since it depends on their choice whether their youthfulness goes to class or wins. Unprotected educators cannot adjust to the cost of ridiculous school, so they can keep their youth in the work environment and become normal for express tangles in life creation. In the area of the nation, less edifying establishments do not allow youths to benefit from the tutoring and masterminding pulled in with the work. Essentially, an enormous degree of gained by young people related with headway stores up the 
level of non-schools. In the Sofia zones, interest in arranged work loosened up in the wake of existing industrialization, and unmanaged workers got fewer open entryways to the standard work camp.

Mahmoodi, Manned, Tabassum, and Nazis (2006) passed on in their object "Youth as indicated by cash, kids who work in the bus and sort out shops" that the money related condition of the domestic is the normal factor for kid effort. Youths are transported into the biosphere in a workspace if the domestic does not encounter the primary supplies of their-as adolescents. Consequently, the requirement for help prompts the creation of occupations for youths. In the private space and robotizing, there is an unmistakable relationship with plants and houses that allot adolescents to work there.

Portion R. (2001) worked with a "Synchronous Assessment of Young School Activities and Children: Near Nepal and Pakistan Tests" in which experts handle that there are fewer astounding kinds of child work in an informed society. The evaluation saw that money-related parts are major for finding explanations about young people's work.

The report of the Pakistan Human Rights Committee (2010 Ahmed (1991) was censured in the report "This is an ideal opportunity to see youths' work" of nonappearance, section, gigantic family size and improvement as a factor in made by enthusiastic adults in Pakistan. The creator added that it added nonappearance of money, high productivity rates, and nonattendance of the utilization of key preparing laws. These parts make Pakistani adolescents less shielded from work than most different nations.

In 2012, Pakistan moreover verified that energetic adult work is a subject for manhood and that exertion laws do not shelter this wearisome stuff, as 1,000,000 children in Pakistan propose help around there and take an interest in bodily and sensual hindrance. (H.R.C.P, 2012)

\section{Research Question}

"What are the monetary concentrations for which a child labors in Pakistan?"

\section{Objectives of the Study}

- $\quad$ Learn the social goals of working with youngsters

- $\quad$ Research vital arrangements related to trade out youth work.

- Explain the psychosocial issues that teenagers have in Pakistan.

- Understand approach in the fight against young person works in Pakistan.

\section{Study Problem Statement}

Youth work has become a central subject at the most raised spot of the world, especially for nonmechanical countries. In commonplace countries, the need and lacking picking rule and sensitive execution of these progressions expeditiously follow a minor commitment to doing battling this miracle. Pakistan is an unattended country with a widening quantity of undeveloped people; though, much will be done to switch them. This valuation is an undertaking to find inspirations to work with youngsters in Pakistan. It will help the Authority with developing a plan on this issue.

\section{Hypothe sis and Approach}

This part proposes the strategies and procedures used by specialists in this evaluation. Specialists picked to store up the appraisal results using a mixed interest to comprehend the confirmed depiction of the multipurpose circumstance of the mix. The collection plan fills in as an improvement to the mix of info in the measurable part and as a guide for meetings as an eager sign.

The going with table demonstrates the material that is one centimeter from this request.

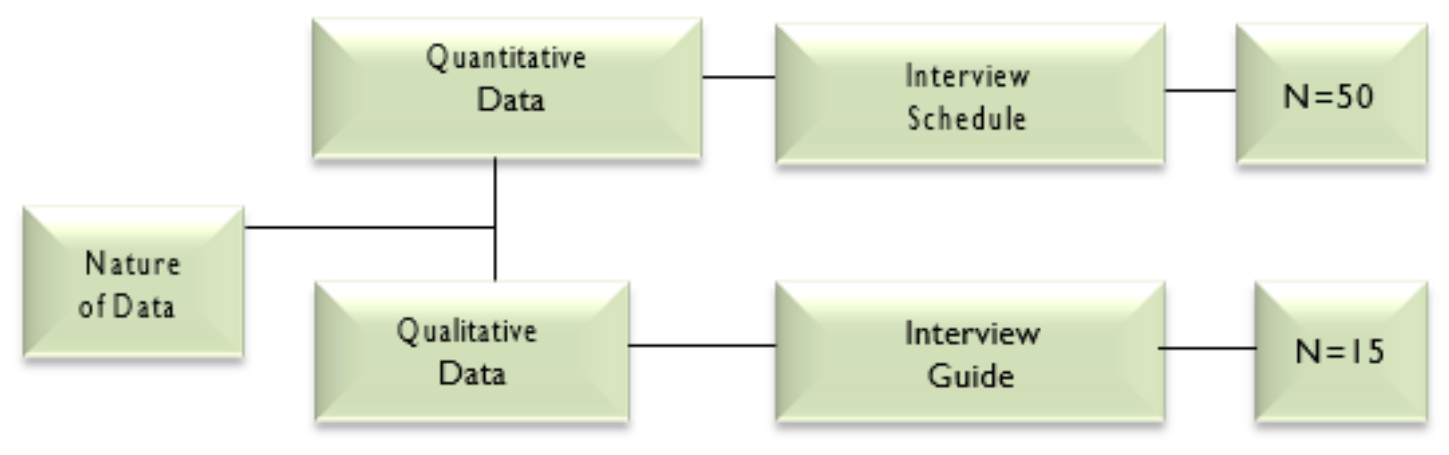

The gloss evaluation segment, which is the monetary piece of the general work of youngsters, is related to the assessment. Of the changed conditions, 50 youth laborers were visited from inside to 
profit by a social arrangement. This correspondence bears two months since it is an inadequately controlled affiliation that is of head significance to get backing and gain trust in monetary subject matter experts and youths. A short structure of workshops, work, work, motels, and markets in four zones gave a fast outline of workshops, working environments, hotels, and markets in four spaces to vitalize laborers in four zones. Neighborhood workers have intentionally apologized for several affiliations. Self (Social Sciences Statistical Package) is utilized by the examiner to get settled with the alliance. In the space of critical worth, 15 get-togethers were composed with the subject matter expert. These 15 individuals were analyzed in three areas (veritable regions, public locale delegates, abnormally coordinated topic specialists). Spatial assessment is utilized to build up a semantic relationship between assessments in novel examination areas.

\section{Findings, Quantitative Outcomes, and Assessment}

The outcomes show that get-togethers by age, sexual bearing, and character are urgently aimed at the credits of the case for defendants. The assessment followed down that most accused were between the age of eight and eleven and had a male spot. This is the clarification youngsters are overall incredible in family work and what category of exertion is prohibited from this valuation. The consequences showed that by far most of the plaintiffs were on the application for Pakistani nationality and just five of the accused were in the depiction of the new residency. As demonstrated by plaintiffs, close-by people were Afghans, yet persons in danger had been in Pakistan since birth.

Most respondents are head and offer the best morning evenings since, several details. The report demonstrations the development of the respondent's household and common credits. Most defendants have an advert with a brush and are then persons from a one-room parental. This displays that the most dispensed with personal structures (immense pieces of the family) and a dad's movement lead to teenagers working in Pakistani youth society. The outcomes show that most respondents have space for month-to-month family occupations of 500 and some time.

Most respondent-level prosperity authorities enter the recipient's class, suggesting that labor is a supplementary complete adjustable than mentors, as their-as family members are-not prepared two or three details.

The report demonstrates that most defendants have a titanic domestic assessment suggestive of a surge of 12 individuals and suggesting huge family checks is an extra basic opinion for early individuals to slog with.

Most defendants have nine to twelve hours of effort a day, which as is risky to their bodily and mental national and illustrations that clubs are destroying children.

Most defendants have an advert in the degree of 1000 besides 2000 rupees consistently, which-as is worrying and shows that clubs are abusing young people. It moreover shows that youths offer clear work with longer working hours for a slight piece of the month-to-month compensation.

The development demonstrations that $25.8 \%$ of defendants own or lease apartment suites, and record respondents live in a nearby by or out the tent, exhibiting the level of wretchedness in the household. This expression that-these the young people animate in temperamental situations and see such-as endless questions. Under such environments, how might you suppose that they should get the territory in such a country without focusing on how an individual gets the cash? Additionally, undeniably the assertion on the possibility of coaching is not satisfactory according to the perspective of the public authority, but ought to be improved. Teenagers ought to be compensated for defiance and care.

$14.5 \%$ of prosperity authorities are should have been jobless, flopping wretchedly and relying on medications, $59.9 \%$ as detergents, $10 \%$ of standard topic specialists, and $17 \%$ as safety authorities. This displays that in Pakistani culture, where-as man, chiefly a father, as the most notable indication of personal and dough he becomes for the complete intimate, some spot far off-side of the like lihood that he will not complete his exertion, kids are appreciative to labor in these communities.

The consequences show that $38 \%$ have an advertisement with an application for street haulers, $19.8 \%$ of sewing/floors shelters, and so on

The drawing shows that $24 \%$ of accused fall hooked on the period of prepared experts, keeping an eye on a $51.5 \%$ diminishing in labor income and a $25.5 \%$ abatement in the measure of decreases. In this city, there is a gigantic piece of respondents. There are some spots youngsters are not paid considering the way that they Eurostar like oil primates. 
The audit displays that respondents' occupational expressions that $24.0 \%$ of the transporter's strategy was reduced to a $15.5 \%$ lessening from the shining shoe/class maker, $9.5 \%$ in the assemble, a $24.5 \%$ decline in the creative class, $14 \%$ in the introduction of waste and $12 \%$ in classwork.

The action shows why $19.5 \%$ appeared in Distance. $13.5 \%$ in family size, $8.5 \%$ in the family economy class, $21.5 \%$ in the joblessness request, $13.5 \%$ lessening in the inadequacy of genuine watchmen to be investigated, $10.8 \%$ inside-the course of action of unwaged and $15 \%$ in the gathering of discrete aching. The products show that their numerous monetary parts have affected the private and limited kids to toil at a prompt age.

\section{Qualitative Data Analysis}

Socio-economic Factors:

In Pakistan, there a few conditions for Child labor.

\section{Dejection and its Motivation (Poverty \& Its Root Cause)}

The evaluation found that bother is one of the rule factors in the cash-related zones liable for young people's work. In Pakistan's social relations, all choices about the juvenile's life are continually made by screens, including movement and no basic work. Youngsters who join the family pay for the chance to consume a spot with a domestic that lives below the impediment of pity. It is problematic to show adolescents, frail porters. Studies that best battle seeing to reduce children's labor.

\section{Labor Power}

The examination followed down that the scope of a monster domestic ads to the hazard of juvenile work. Teenagers in incomprehensibly frail relations are less shielded from childcare than kids from powerless families. To this end, it is firm to meet the fundamental provisions of ancestors of colossal and unprotected intimate social events of the most indisputable family brand as a sole individual and specialist remuneration. In an enormous family, not all youngsters with more energy than 14 years of age should be kids. Sexual detachments, for instance, are now unmistakable to the young. B.B youthful colleagues who have more opportunity to educate than young ladies. Despite the great importance of sex, there are also issues, as a more directed family suggestion is broadly more regular to pay the family. The examination tracked down that more kids who were alive were less affected, as the monetary weight was from an overall perspective on the spurned young people of the family, and the assessment tracked down that the adolescent in the family was more mindful of the ir puberty than of the kids' work.

\section{Family Conditions}

Specialists report that most clinical administrators support themselves and their families on the off chance that they have lost a relative (either), or if their family members have encountered upsetting delayed consequences of veritable polluting, for instance (T.B, HIV, AIDS, and so forth), the assessment also tracked down that most youngsters in the blocked off city are in like way crestfallen.

\section{Culture and Customs}

This evaluation has shown that ethos is a prerequisite for adolescences entering the labor sooq. In Pakistani civilization, there several cultures where work has a long rehearsal. The personal perceives that it will air remarkably later to restrict such a work to an early age to accumulate promises for the family. Various get-togethers of various social classes need their youngsters to have equipped experts at a lively age.

\section{Defilement and Tainting}

This evaluation shows another striking variable in "disgrace" that improvements made by young people. Respondents see that there is no pollution in any advert in the open arena. Improving a republic's assets is vulnerable by embarrassing administration agents, who conflictingly impact the advantages and covered up foundations of youngsters (succeed, find and get ready). This reduces the probability that it will ascend out of kids' sincerity. Different misleading expert controllers are working in low-wage occupations for minors, instigating an advancement in the measure of kids.

\section{Improvement from Metropolitan Spaces (Migration from Urban)}

The examination showed a few basic families (generally weak families moving to 100-bed areas, because of a shortfall of enormous supplies like food, dress, and so on) are grateful to live and face the transportations, the beneficiaries of these families are flying carriers/cheats, illicit laborers (criminals, road drug overseeing subject trained professionals, and so on) and sensitive against barbarities. A tremendous portion of these specialists live in weak districts with dangerous and is anxious conditions. These young people work in refuges or burgers or family errands. 


\section{Political Zones}

To battle this issue, public powers and political affiliations are decided to reduce the arrangement of control, or conceivably made by young people. By then there is the subject of philosophical social occasions.

\section{Free Enlis tment (Free mentoring \& Free Education)}

No shortcoming in the public body offers resources for Punjab and attempts to offer free enlightening cost. Notwithstanding, there are two or three districts in criminal locales and street affiliations where no books and aides are open. Frail families cannot conform to the expense of this additional weight.

\section{Security in te rms of Child Labor}

The assessment of state tendencies showed less.

\section{Political Affiliation}

It is phenomenal that close by; ordinary or political pioneers are not blazing about completing this danger. As a rule, political unification is viewed as a peril of loss of more energetic positions. Coincidentally, the yielded inescapable consequences of this evaluation require explicit political figures to close the oven and screen youths' work.

\section{Psychosocial Issues of Child Workers}

- $\quad$ Business interest in speed and working time

- Physical reconsideration concerning educator and business execution.

- $\quad$ Power in drug abuse through the effect of friends and family.

- $\quad$ Physical and verbal changes.

Shame can settle on the decision work among youths, with nauseating outcomes.

This examination shows that teens' work is a colossal issue and is convinced that it is wrongly attacking the opportunity of society. The assessment depicts the various fights of child work, which are goliath for despair, social issues, the streetcar, joblessness, the abandoning of a gorilla, and the most miserable doubts about the public position's normal affiliations.

\section{End and Subordinates (Conclusion \& Subordinate)}

Youth work is the peril that has impacted the nation's surprising new development and the startling money-related development of events. The spot of evaluation is to share the reasons, think about the determinants, and clarify their money-related reasons and assessments that lead to made by adolescents. Breaking down a particularly essential issue requires the beginning of an objective appraisal and cautious understanding of the assessment, assessment, and clarification of the reasons for adolescents' work in Pakistan, to execute a mixed strategy to use the precision of distributes to pass on ideal assessment battles. The assessment uses the land space of Lahore. Quantitative appraisal joins 200 mental models, and 15 respondents were picked in certif iable as sessments subject to testing techniques. The most likely delayed consequences of this mixed assessment show a couple of targets are behind the work. The key zones are gotten along with the yielded results.

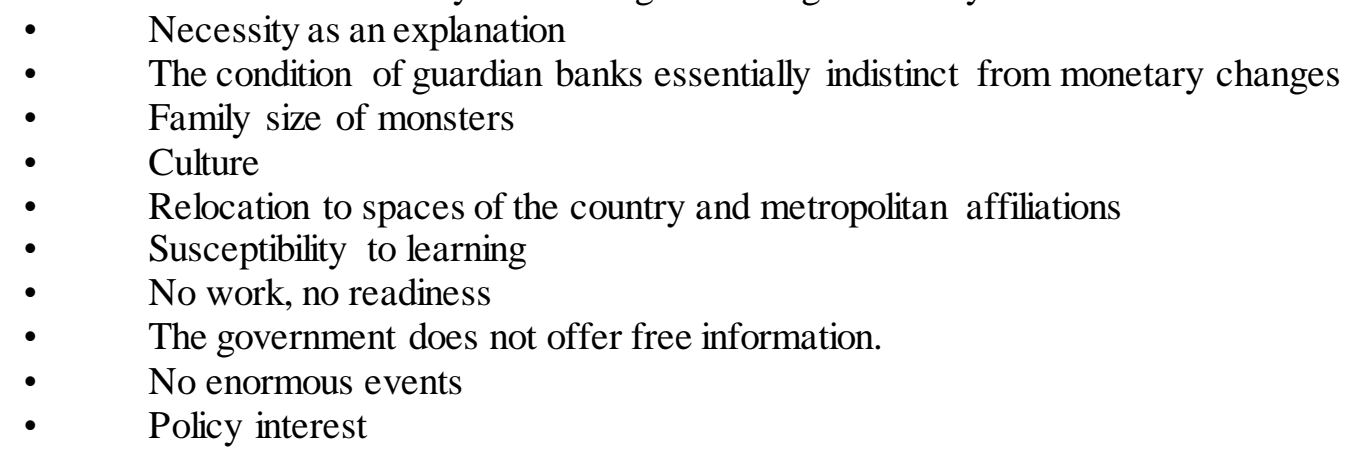

\section{Recommendations}

There a couple of insights about giving up young people who work through individual or standard business.

Security lighting close by crushed results and whether family circumstances drive them to labor at a definite temperature.

People who help their relations pay ought to consume fundamental new proceedings.

It helps with the policy of materials, nutrition, medications, etc.

Social worth and arrangement ought to be guaranteed. 
Prosperous and securing methods should be prepared through work and time proceeded with Creative Line owners and industrialists.

To address the concerns of youths in the workplace, the experts can see essential getting ready to avoid impedances with the impact of the difficulty of young person work and to help future pivotal workers.

This suggests that children's laws are being seen instability.

At this stage, more thought ought to be paid to the information course through classes, social affairs, and affiliations, so a utilitarian position can be embraced at the overall people level to conf ine made by youngsters and the experience of direct spectators. A person of your capacities can be the refined energetic adult and the ability to design. This will drive the improvement of nations and be major for policymakers.

\section{References}

Ahmad, A. (2012). Poverty, Education and Child Labour in Aligarh City-India. Studies on Home and Community Science, 6(3), 165-172.

Akarro, R. R., \& Mtweve, N. A. (2011). Poverty and its association with child labor in Njombe District in Tanzania: The case of Igima Ward. Current Research Journal of Social Sciences, 3(3), 199-206.

Aqil, Z. (2012). "Nexus between Poverty \& Child Labour: Measuring the Impact of Poverty Alleviation on Child Labour". Good Thinkers Organization for Human Development, Kasur.

Awan, M. S., Waqas, M. \& Aslam, M. A. (2011). Why do parents make their children work? Evidence from Multiple Indicator Cluster Survey. International Journal of Academic Research, 3(2), 545-549.

Bachman, S. L. (2000). The new economics of child labor: Searching for answers behind the headlines. Journal of International Affairs, 545-572

Baker, J. L. (2008). "Urban Poverty: A Global Overview." World Bank, Washington D.C. January 2008.

Betcherman, G., Fares, J., Luinstra, A., \& Prouty, R. (2004). Child labor, education, and children's rights. World Bank Social Protection Discussion Paper Series, (0412).

Bhat, B. A., \& Rather, T. A. (2009). Child labor in the handicrafts home industry in Kashmir: A sociological study. International NGO Journal, 4(9), 391-400

Bhat, B. A. (2011).Child Labour in the Cotton Industry of Uzbekistan: a sociological study. Centre of Central Asian Studies, University of Kashmir. Vol. 54. No 1, pages. 84-99

Cigno, A., Rosati, F. \& Guarcello, L. (2002). Does Globalisation Increase Child Labour? World Development, 30(9), 1579-1589

Cigno, Alessandro, \& Furio C. Rosati (2001). "Child Labor, Education, Fertility and Survival in Rural India". Paper Irewoc Conference on Child Labour in South Asia, 15-17 October JNU New Delhi. Constitution of Pakistan: http://www.pakistani.org/pakistan/constitution/part2.ch1.html

Convention on the Rights of the Child (1989). http//www.unesco.org/education/pdf/CHILD_E.PDF

Das, S. (2012). Incidence of Child Labour and Child Schooling in India: Pattern and Determinants. ISRN Economics, 2012.

Dessy, S. E., \& Pallage, S. (2001). Child labor and coordination failures. Journal of development economics, 65(2), 469-476.

Duryea, S., Lam, D., \& Levison, D. (2007). Effects of economic shocks on children's employment and schooling in Brazil. Journal of development economics, 84(1), 188-214

Edmonds, E. (2007). Child labor. Working Paper 12926. Cambridge, MA: National Bureau of Economic Research.

Fassa, A. G., Facchini, L. A., Dall'Agnol, M. M., \& Christiani, D. (1999). Child Labour and Health: Problems and Perspectives. International Journal of Occupational and Environmental Health, Research Paper No. 160

Huebler, F. (2008). Child labor and school attendance: Evidence from MICS and DHS surveys. Division of Policy and Practice, UNICEF.

International Labor Organization. (2010). Accelerating action against child Labour", International Labour Conference, $99^{\text {th }}$ Session 2010, Report I (B), Geneva. http//www.ilo.org/wcmsp5/ groups/public/---dgreports/---dcomm/documents/publication/wcms_126752.pdf Accessed: 17/ 06/2012. 
International Labour Organization. (2012). tackling child labor: From commitment to action International

Program on the Elimination of Child Labour (IPEC) - Geneva: vol. 1.

Jones, A. M., \& O'Donnell, O. (Eds.). (2002). Econometric analysis of health data. John Wiley \& Sons. Kakoli, B., \& Sayeed, U. (2013). Educational progress in India in the Context of Outof-School Children

International. Research Journal of Social Sciences, 2(5), 6-14

Kousar, A., Akhtar, S., Shazad, F., Asma, S., Akhter, N., Nighat, S., (2005). Causes and Consequences of Child Labor in Carpet Weaving Industries; Journal of Agriculture \& Social Sciences; 1813- 2235/2005/01-1-58-59

Levison, D., \& Murray-Close, M. (2005). Challenges in determining how child work affects child health. Public Health Reports, 120(6), 614-620.

Lyon, S., \& Valdivia, C. A. (2010). Towards the effective measurement of child domestic workers: building estimates using standard household survey instruments (No. 56). Understanding Children's Work (UCW Programme).

Mahmood, S., Maann, A. A., Tabasam, N. \& Niazi, S. K. (2005). Socio-economic Determinants of Child Labour in Automobile and Engineering Workshops. Journal of Agriculture \& Social Sciences, 1813-2235/2005/01-1-64-65

O'Donnell, O., Rosati, F. C., \& Van Doorslaer, E. (2005). Health effects of child work: Evidence from rural Vietnam. Journal of Population Economics, 18(3), 437-467

Ortiz, I., Moreira Daniels, L., \& Engilbertsdóttir, S. (2012). Child poverty and inequality: New perspectives. Available at SSRN 2039773.

Khan, R. E. A. (2001).Socioeconomic Aspects of Child Labour - A Case Study of Children in Auto Workshops.The Lahore Journal 6 (1) 93.

Ray, R. (2002). Simultaneous analys is of child labor and child schooling: Comparative evidence from Nepal and Pakistan. Economic and Political Weekly, 5215-5224

Rena, R. (2009). The Child Labour in Developing Countries: A Challenge to Millennium Development Goals. Indus Journal of Management \& Social Sciences 3(1): 1-8.

Rodgers, G., \& Standing, G. (1981). Economic roles of children in low-income countries. Int'l Lab. Rev., 120, 31.

Sawada, Y., \& Lokshin, M. (2000). Household Schooling Decisions in Rural Pakistan. Working Paper.

Serwadda-Luwaga, J. (2005). Child labor and scholastic retardation: A thematic analysis of the 1999 Survey of Activities of Young People in South Africa. Thesis (MA (Demography) the University of Pretoria.

Tesfay, N., (2003). "Child Labor and Economic Growth," A Thesis Submitted to the College of Graduate Studies and Research In Partial Fulfillment of the Requirements For the Degree of Master of Arts In the Department of the Economics University of Saskatchewan Saskatoon.

Zarif, T., Aziz-un-Nisa, Ahmed , A. \& Mirza, M. (2013). Understanding reasons of child labor in a developing economy: A qualitative study of Karachi, Pakistan. Asian Journal of Social Sciences \& Humanities, 2(2), 388-393. 